\title{
"Alexa, who am I?": Voice Assistants and Hermeneutic Lemniscate as the Technologically Mediated Sense-Making
}

\section{Olya Kudina $^{1}$}

Accepted: 31 January 2021 / Published online: 23 February 2021

(c) The Author(s) 2021

\begin{abstract}
In this paper, I argue that AI-powered voice assistants, just as all technologies, actively mediate our interpretative structures, including values. I show this by explaining the productive role of technologies in the way people make sense of themselves and those around them. More specifically, I rely on the hermeneutics of Gadamer and the material hermeneutics of Ihde to develop a hermeneutic lemniscate as a principle of technologically mediated sense-making. The lemniscate principle links people, technologies and the sociocultural world in the joint production of meaning and explicates the feedback channels between the three counterparts. When people make sense of technologies, they necessarily engage their moral histories to comprehend new technologies and fit them in daily practices. As such, the lemniscate principle offers a chance to explore the moral dynamics taking place during technological appropriation. Using digital voice assistants as an example, I show how these AI-guided devices mediate our moral inclinations, decisions and even our values, while in parallel suggesting how to use and design them in an informed and critical way.
\end{abstract}

Keywords Hermeneutic lemniscate $\cdot$ Technological appropriation - Technological mediation · Value change $\cdot$ Voice assistants $\cdot$ AI

\section{Introduction}

Digital voice assistants (DVAs) redefine the way we interact with technologies, presenting voice as the primary interface. Natural language processing algorithms and other forms of Artificial Intelligence underlying DVAs allow people to use phones for dictating messages rather than typing them or asking the phone to set

Olya Kudina

o.kudina@tudelft.nl

1 Department of Values, Technology \& Innovation, Section On Ethics and Philosophy of Technology, Delft University of Technology, Building 31, Jaffalaan 5, 2628 BX Delft, The Netherlands 
an alarm. Increasingly, voice interfaces permeate the homes of people in a form of smart speakers, such as Amazon's Echo with Alexa as a virtual assistant or Google's Home with Google assistant. But beyond turning on the lights and informing how far the nearest pizza place is, DVAs also change the way we interact with each other.

Even though the first DVAs appeared only a few years ago, there are already signs of their social—and ethical—implications. Voice assistants process users' speech as commands or requests, discrediting the accompanying niceties, jokes or sarcasm as non-functional statements. The users learn that if they want Siri or Alexa to understand them, they need to be as concise as possible. However, DVAs are not perfect in processing human speech, often asking to repeat the questions multiple times and unchallengingly accepting angry or offensive responses from the users. Most often, this is done in a female-sounding voice. As I will argue in this paper, such design features of DVAs recontextualize the meaning of the world to the users that in turn, helps to shape them as specific subjects. This may change not only how we understand ourselves but also what we expect from those around us. While the adoption of DVAs is still ongoing, in this paper, I explore philosophical challenges regarding the shift to voice-first interaction, particularly the inclusion of technologies in the sensemaking processes of people.

To do so, I will build on the field of philosophy of technology (e.g., Dreyfus 1972; Borgmann 1984; Ihde 1993; Hasse 2008; Rosenberger and Verbeek 2015) and will specifically draw on and contribute to the approach of technological mediation (Ihde 1979, 1990). I focus on the technological mediation approach because it asserts an interactionist perspective on technology, acknowledging the role of both people and technologies in the joint production of reality, without either one independently determining its subjects and objects (see McLuhan 1994/1964; Benjamin 2008/1936). Technologies, by virtue of their design features, help to highlight certain aspects of reality, while concealing others, but it is upon people in specific embodied sociocultural spaces to interpret that message and act on it (Rosenberger and Verbeek 2015). In line with a slogan "It could have been otherwise" from the field of Science and Technology Studies, technology never determines how users adopt it-even though it scripts user behavior, it is only in the social-technological co-shaping and negotiation that specific technological effects materialize (Bijker, Hughes and Pinch 1987; MacKenzie and Wajcman 1985).

Interpreting the co-shaping of people and technologies philosophically on the axis of perception-action (Ihde 1993), the mediation approach additionally makes room for exploring how specific moral perceptions and actions emerge in humantechnology relations (Verbeek 2008). Consider how a shift from a written to spoken interface in the case of DVAs and other virtual agents makes adult users perceive them as more trustworthy and increase their proclivity to share personal information (Nass and Brave 2005). Similarly, regardless of the outer appearance as a plastic box and the robotic glitches in the voice, Druga and colleagues (2017) showed how the voice-based interface and the unchallenged answering of non-stop questions increase the anthropomorphism tendencies of children towards DVAs, generating trust and authority in the device akin to role models. The hardware and software, type of interface, physical appearance and algorithmic underpinning all enable specific technological practices, magnifying some aspects of reality or suggesting 
certain use patterns, while reducing the visibility of the alternatives. The non-neutrality of technological design renders technologies as mediators of our relation to others and the world, while retaining the active role of people and their sociocultural setting in co-producing these mediations (Ihde 1990), including their moral dimension (Verbeek 2011).

I suggest that examining closer how people make sense of technologies can shed light on how moral sensibilities and concerns come to the fore. For this reason, I will introduce a concept of "technological appropriation" in the hermeneutic tradition of philosophy to show how people attribute technologies with meaning and make them their own. Appropriation ${ }^{1}$ will thus open up the interpretative dimension of technological mediation, necessary to maintain an engaged yet informed and critical relation with the devices we use.

Thus, the paper attempts to find a role for technologies in the sense-making processes of people. To do so, I will first explore how the concept of technological appropriation, the hermeneutics of Gadamer and the material hermeneutics of Ihde can be helpful in this regard ("Finding a place for technologies in the process of sense-making" section). Combining the insights, I will next offer a novel theoretical account of how technologies mediate the meaning-making processes of people, which I will call the technologically mediated "hermeneutic lemniscate" ("Mediated meaning as a hermeneutic lemniscate: from people through technologies to the world-and back" section). The lemniscate principle of interpretation is different from the hitherto available accounts in that it considers the active mutually informing roles of people, technologies and the sociocultural world in the formation of (moral) meaning. I will illustrate this by exploring the case of DVAs to outline how they influence our perceptions, actions and moral intuitions through specific technological mediations. Finally, in the "Concluding discussion" section, I will reflect on the broader philosophical implications of the lemniscatic principle, as well as on the use and design of voice assistants.

\section{Finding a Place for Technologies in the Process of Sense-Making}

To find a place for technologies in the interpretative schemes of people, particularly pertaining to the moral sense-making, it is first important to clarify how technologies are connected to the moral world. Taking cue from the pragmatist thought of Dewey, values are the building blocks of morality, "ends in view," the evaluative devices that both guide our practices and are produced in their sociomaterial entanglements (1922). Such a practice-based approach to moral world "encourages us to regard the ethical problem as the question of creating and taking care of social routines, not as a question of the just, but of the 'good' life as it is expressed in certain body/ understanding/things complexes" (Reckwitz 2002: 259). The technological mediation approach offers a starting point in elucidating the ethical role of technologies

\footnotetext{
1 To be distinguished from the same term in the domestication field of the Science and Technology Studies, discussed in Sect. 2.
} 
in moral practices: "If ethics is about the question of 'how to act' and 'how to live,' and technologies help to shape our actions and the ways we live our lives, then technologies are 'actively' taking part in ethics" (Kudina and Verbeek 2019: 297). By helping to shape moral inclinations and decisions, technologies mediate morality: prenatal genetic testing mediates moral questions and decisions about childbearing, (semi)autonomous robots mediate the moral experiences of war and CCTV cameras mediate public behavior.

Yet, as explained by Mol (2002) and Dussauge and colleagues (2015), there is no direct access to values-in-practices, as there is no mental beeline to locating technologies in the minds of people. It seems that the hermeneutic infrastructure that could imbed the role of technologies in the interpretative schemes in general and their moral dimension in particular, is still missing. This requires locating technologies in the process of interpretation, related to existing human experience and the larger sociocultural embedding. I suggest that clarifying first how people make technologies their own, conceptually and practically, can open the way to understanding the relation between sense-making and technologies. For this reason, I turn to the concept of technological appropriation.

\section{Technological Appropriation, or How We Cannot Avoid (re)Inventing Ourselves While Making Sense of Technologies}

The concept of appropriation has a firm standing in the field of STS, particularly in the framework of domestication (e.g., Silverstone and Hirsch 1994; Sorensen 2006; Berker et al. 2006). Here, appropriation concerns one of the stages of domesticating technology, at a point of its sale and bringing it into one's home. While appropriation is here predominantly concerned with the social negotiation of the accepted meaning of a technology (Silverstone, Hirsch and Morley 1994: 18f.; Hahn 2012), its ethical dimension remains behind the spotlight. While understanding the home adoption of technologies is important, it is equally crucial to understand their role in the broader interpretative schemes of people. Beyond sociological, this requires a philosophical attention from the domain of hermeneutics that systematically studies the nature and principles of interpretation.

With this in mind, I introduce the concept of appropriation in the philosophical domain, defining it as a projective and practical dimension of human interpretation that allows us to make technologies our own by attributing them with meaning and continuously revising it. During appropriation, people interpret a (new) technology and integrate it into the existing frameworks of understanding, necessarily updating them. The process of appropriation thus resembles the mutually informing symbolic, cognitive and practical activities. It is an intentional activity of relating to technologies during which moral concerns and perceptions manifest themselves and existing normative ideas can undergo re-articulation and change.

The sense-making activity regarding a certain technology starts when there is any information about it in the media or elsewhere, even in its physical absence. For this reason, I distinguish between two mutually informing dimensions of appropriation, projective (e.g., conceptualizing, comparing, fostering new meanings, reconfiguring 
existing ones, etc.) and practical (e.g., physically approaching a technology, understanding it through use, etc.). In the context when new technologies appear almost daily, people often deal not with the technology itself but with the promises, hopes, visualizations, video presentations, scenarios, debates, concerns and fears regarding the new device. Before the technology enters the market and the household, people already have an idea regarding what it is and how it fits (or does not fit) with their mindset and moral landscape. By accounting for both the projective and practical dimensions of sense-making, appropriation allows to examine how "technological potentialities" (Kiran 2012) help to shape specific human subjects before and during technological use.

Appropriation is closely linked to the ethical implications of technologies because it inevitably embeds the moral sense-making. Hermeneutically speaking, appropriation represents a circular activity (Gadamer 1975/2004), whereby people comprehend an unknown by projecting their own histories and personalities onto the sociotechnical environment, continuously revising preliminary meanings with new information and practical experiences. It thus captures the dynamic balance between the existing experience, perceptions and knowledge of people, including normative views, and the cumulative unknown that a new technology represents in a given context. Because values are an inalienable counterpart of our sociocultural and individual histories, attempting to understand a technology also engages normative intuitions, makes them visible and available for renegotiation.

Such conceptual investigations elucidate several points related to technologies and meaning-making. Firstly, the sense-making activity underlying technological appropriation involves the interaction of (at least) three actors: people, with their epistemic structures and beliefs; technologies, representing a phenomenon that requires integration into the epistemic and practical frameworks; and the sociocultural world, as an active context against which a specific human-technology encounter occurs. Secondly, the three dynamic and interrelated elements of the appropriation process prevent it from being a static, final event. People can reconsider the meaning and place of a certain technology in their life once the existing meaning no longer fits the current situation. The stability of a preliminary meaning bestowed upon an artefact depends on the interaction between people and technology in a specific sociocultural setting. However, the appropriation remains an open process.

Technological appropriation thus appears a promising concept to further untangle the relation between technologies and the (moral) sense-making. However, the philosophical principles underlying the appropriation process require more elaboration. Relying on the example of voice assistants, I will now turn to the hermeneutics of Gadamer $(1975 / 2004,1977)$ and the material hermeneutics of Ihde $(1990 ; 1998)$ to see how they account for the sense-making processes of people.

\section{Hermeneutics and Gadamer's Circular Account}

I would like to briefly explain the hermeneutical foundation of the nature of interpretation and suggest that it requires an expansion to address the challenge of considering the role of technologies. Gadamer's hermeneutics is particularly useful here 


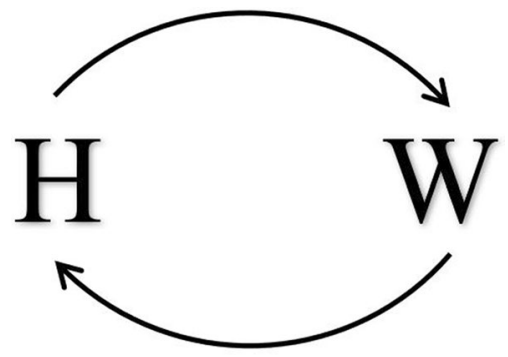

Fig. 1 Hermeneutic circle account of human-world interpretation

because it explains the dynamic nature of interpretation, its historical imbedding and the role of productive prejudices.

Gadamer (1975/2004, 1977) was primarily concerned with clarifying how people understand the world, ${ }^{2}$ how exactly the interpretation process occurs. His answer was the principle of the hermeneutic circle, an adaptation and expansion of the similar idea of Heidegger (1927/1962). People always have ideas about a phenomenon that confronts them, see something as something. Interpretation, then, is a constant movement of recognizing the parts to form a whole picture, only for it to become a part of something new again. The seemingly established ideas are in fact dynamic and open to revision once a new situation questions them. Gadamer described this intertwined establishment-and-revision process as circular, whereby the new meaning joins the existing knowledge structures for the future interpretations of new experiences. Thus, the circle is never complete, and an established understanding is never stable.

Gadamer's hermeneutics stresses the productive nature of understanding. People are historically embedded beings that cannot escape traditions and frames of reference, be it our collective morality, gained knowledge, experience, perceptions and own normative ideas. Within the historical embedding, Gadamer distinguishes the essential and productive role of prejudice, discarding its modern negative interpretation in favor of its ancient meaning as prior awareness, or pre-judgment (Gadamer 1975/2004: 273). Prejudice thus denotes the cumulative potential of the preconceptions, provisional judgments and biases that inalienably direct people to the new phenomena. Although it is never possible to completely disregard our prior awareness, it is critical to attempt to recognize and expel existing biases to view a new phenomenon on its own terms. Viewed as such, prejudice enables the dialogue with the confronting phenomena rather than constituting a hindrance to interpretation: "It is not so much our judgments as it is our prejudices that constitute our being" (Gadamer 1977: 9). Combined, the ideas of historical embedding and prejudice understood as pre-judgment allow an entry into the mindset of another time, place or object within the hermeneutic circle.

\footnotetext{
2 Although Gadamer primarily referred to textual interpretation in understanding the world, his hermeneutic account has been applied in a broader sense to any particular object in the world (Fry 2009).
} 
However, the hermeneutic circle account assumes that interpretation is a direct, albeit a circular, process: from the interpreter to the world, and back (see Fig. 1). For instance, in using DVAs, the world can be represented in many ways: e.g., inquiring about the weather, listening to music, contacting other people or learning about the current events. Yet the technologically-facilitated manner in which the world appears for the person to make sense of does not get a place in the hermeneutic circle. DVAs, by shifting the mode of interacting with technologies to speaking, expand human interaction with the world with new opportunities for engagement without the distraction of typing or swiping. They provide the opportunity to manage music without exiting the shower, deepen the embodiment of one's home through connecting spaces and devices ${ }^{3}$ by voice (e.g., turning on the coffee machine), arrange home security at distance (e.g., scheduling home lighting), listen to a book while doing the dishes or connect to other people in the same space while playing games through DVA together. At the same time, the new voice-based interface co-produces the experiences, the accompanying perceptions and responsibilities in accessing the world and others.

A voice-based interface both presents the world in a specific way and requires a certain manner of interaction. A user is not simply listening to the music, but needs to first frame a request to put it on in a specific way (e.g., Hey Google, play a song X by artist $\mathrm{Y}$ from the album $\mathrm{Z}$ ) and say it in a clear way void of accents or sound variation for the DVA to be able to process it. Spatially, the user needs to ensure that the surrounding environment does not have parallel conversations or loud music already on, place the speaker in the room accordingly, count on a stable internet connection and that the DVA processes the request correctly from the first try. In the hermeneutic circle account, a meaning of the experience of listening to music is uncovered through a dialogue between the user and the artist: the former working out her prior judgements within the expression style of the latter. What is omitted, however, is the technological medium through which this circular process occurs, leaving it a direct sense-making between a human and the world.

The hermeneutic circle account stresses the productivity of the context that coshapes a given meaning-making situation. If we consider this point seriously, the material setting forms not only a passive context of accessing and interpreting reality but actively contributes to the process. Without a material dimension of interpretation, the hermeneutic circle does not provide an encompassing account of sensemaking. With this in mind, I turn to the field of material hermeneutics and, more specifically, to the postphenomenological account of Ihde that focuses on an active role of technologies in interpretation.

\section{Postphenomenology and Ihde's Human-World Relations}

Since the introduction of information and communication technologies in the 1960s and 1970s, the hermeneutic approach has developed in scope. In particular,

\footnotetext{
3 There is a range of third-party household appliances that can be connected through internet to DVAs, e.g., a bathtub, a thermostat, a coffee-machine, security systems, etc.
} 
the works of Dreyfus (1972; 2001), Borgmann (1984; 1999), Ihde (1979; 1990) and Capurro (2010) have advanced the field of hermeneutics beyond the interpretation of text and have contextualized human interpretation within an increasingly technological environment. Dreyfus (1972) highlighted the importance of information technologies in producing the contexts and practices from which people draw knowledge, framing technologies as annihilating "vulnerability and commitment," essential for interpretation and understanding (2001: 102). Borgmann stressed the hermeneutic potential of technologies in enabling or disabling social practices (1984) and fracturing contexts of understanding between the "real" world of people and the virtual world of technologies (1999). According to Ihde, who developed the idea of technological mediation, reality appears as a technologically mediated product or image to interpret, calling for an introduction of "thing interpretation" (1998: 8), "instrumental visual hermeneutics" (1998: 177) and "a hermeneutics of things" (1998: 187), or in other words, material hermeneutics (Verbeek 2003). According to Capurro, technology produces (in)visible networks that people cannot fully control and thus weakens people as the interpreters of the world (2010: 36).

While this short account of the recent developments in hermeneutics is by no means exhaustive, it depicts an important shift: the acknowledgment of the significance of technology in the process of making sense of the world and oneself in it. Dreyfus and Borgmann consider technology alienating and a hindrance to understanding. However, they do not specify how to identify a place for the increasing presence of technologies in the interpretative frameworks of people. Capurro, in contrast, withdraws from normative valuations and stresses the ontological nature of technologies, in parallel reducing the productive role of people in the process of interpretation. Ihde's account of technologies as mediators seems to provide a nonreductionist view of the role of technologies in interpretation that may also help to understand better the human appropriation of technologies.

Ihde $(1990 ; 1993)$ analyzed the relations between people, technologies and the world within the framework of postphenomenology. This framework builds on phenomenology in exploring the lifeworld of people but extends it further to account for the ever-increasing intertwinement of human lives with technologies. Contrary to Gadamer, Ihde suggests that human-world relations are not direct because technologies play an active mediating role in how people perceive, interpret and act in the world. Postphenomenology and the technological mediation approach aim to explore how technologies co-shape the reality of people.

To analyze how technologies mediate human existence, Ihde (1990) distinguishes four types of human-technology-world relations: embodiment, where a technologyin-use disappears from view and becomes a transparent counterpart to the human experiences (e.g., a pair of glasses); hermeneutic relation, where a person interprets the world through a technology (e.g., a computer); alterity, where a person interacts with a technology to access the world (e.g., ATM); and background, where technology forms an active backdrop of human experiences and becomes noticed only when malfunctioning (e.g., Wi-Fi). In what follows, I focus on the hermeneutic relation as 


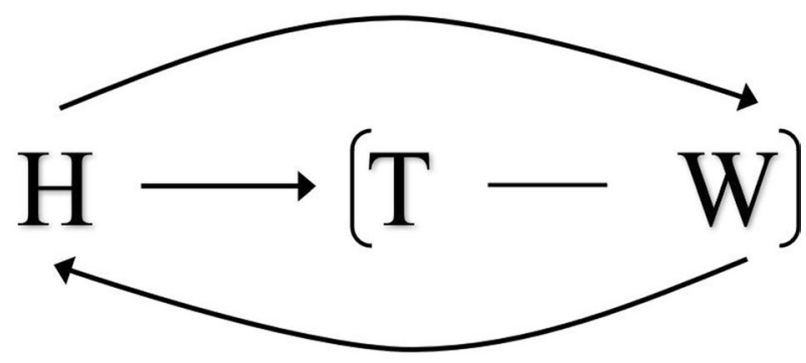

Fig. 2 Material hermeneutics account of human-technology-world interpretation

the most pertinent to the study of sense-making, bearing in mind that all four relations may be viewed from the material hermeneutics angle. ${ }^{4}$

For Ihde, technologies are "perception-mediating and perception-transforming devices" (1998: 185). Ihde suggests that perception originates within interconnected yet different "bodies:" "Body One" and "Body Two." Body One refers to the sensomotorial physical body, or a perceptual bodily awareness, "a being-here, located, sensory being with specific styles of movement" (Ihde 1998: 89). Body Two concerns a lived, social body enriched with the history and culture surrounding it. Examining perception through two bodies mirrors Ihde's earlier conceptualization of perception as consisting of both the micro and macro levels (Ihde 1990). Ihde's combined view on perception would regard microperceptions as pertaining to the perceptual bodily awareness of Body One, and macroperceptions to the culturally and experientially informed Body Two. Interpretative activity depends upon the dynamic interrelation of the two bodies, both sensorial micro- and cultural macroperceptions.

The hermeneutic relation represents another caveat to Ihde's hermeneutics, which is typical for all four types of relations: while technologies mediate how people relate to the world, it is unclear how the mediated world finds its way back to people. When technologies mediate what appears to us as real and co-shape our object of interpretation, the mediated interpretation cannot go unnoticed for the reference schemes in our micro- and macroperception that embody all lived experience and prior awareness. Particularly in the context of interpretation, the linear scheme in human-technology-world relation seems problematic.

In his 2005 book What things do?, Verbeek expands postphenomenology by asserting that people and technologies co-constitute each other. No pre-given subjects exist who act upon the passive objects in the world: "What the world 'is' and what subjects 'are,' arises from the interplay between humans and reality" (Verbeek

\footnotetext{
${ }^{4}$ Relating Ihde's broad definition of material hermeneutics to the fourfold scheme of human-technology-world relations means that each of these relations can be viewed from the angle of material hermeneutics. The hermeneutic relation would explicitly review the technological mediation of interpretation. The embodiment relation would inquire into how the person reveals herself to the world and the world to her through incorporated technologies. The alterity relation with hermeneutics in mind would be enabled when the technological design communicates certain practices with this technology. Finally, the background relation would uncover the silenced blending of technologies with our environment.
} 
2008: 13). Applied to Ihde's material hermeneutics, the co-constitution principle replaces the relations of linearity with circularity. However, it is not clear how the principle of co-constitution functions. Figure 2 below schematically represents Ihde's hermeneutic "human (technology-world)" relation (1990), overlapped with Verbeek's co-constitution idea (2005).

Figure 2 represents the inclusion of technologies in the sense-making processes of people through the perspective of mediation. The outer world appears to the DVA user not directly, but via a gendered voice of the device, commands of the smart speaker, a crafted persona of the DVAs and its design exigencies (e.g., connection to electricity and Wi-Fi, speaking loud enough, etc.). The world, in Ihde's words, appears as "framed" because "what is presented is presented as already distinct from ordinary or lived-bodily space" by virtue of "limited and selected-out framing" and "an on/off presentation" (1998: 91, original emphasis). DVAs mediate perception of the user because they simultaneously reduce the sensory and audio experiences by framing the world through its particular design and modes of presentation, and magnify it, by allowing access to the world that is not available to the naked eye or touch.

In Fig. 2, the circular arrows around Ihde's "human $\rightarrow$ (technology-world)" relation (1990) represent Verbeek's co-constitution idea (2005). Here, the historical and cultural Body Two allows appropriating the socially positioned device and the messages it produces. The sensomotorial Body One, on the other hand, accounts for the physical interaction with the DVA ensuring issuing of commands such that the speaker can process them (e.g., language proficiency, tone, speed, clarity) and optimal functioning of the device for the user (e.g., privacy settings, wake-up word, voice settings, battery charge, etc.), which together contribute to the process of interpretation. As such, both the sensomotorial Body One and the experiential, sociocultural Body Two produce meaning. However, while Verbeek augments Ihde's material hermeneutics by acknowledging the continuous dialogue between the different counterparts of mediation, he does not explain how such a feedback channel functions and leaves the issue of linearity unresolved.

In the case of DVAs, the linearity of the human-technology-world relations disembodies the users from their physical bodies (Body One) and their sociocultural setting (Body Two) by precluding the feedback through the DVA among the user and the world. An expansion of voice-based interfaces introduces a new manner of experiencing the world, while at the same time constituting specific types of subjects that would fit the technologically mediated spoken interaction and excluding those beyond a category of a standard user. Current speech recognition systems are poorly equipped to process the speech variance and impaired speech intelligibility due to, e.g., oral cancer (Halpern et al. 2020), cleft lip and palate (Schuster et al. 2006) or stroke survivors (Jacks et al. 2019). In the current scheme of human-world relations, a near inability of DVAs to process pathological speech or speech variance breaks down access of certain users to the world, an example of linearity in absence of further underlying embedding of Body One in the sense-making process. Regarding the sociocultural Body Two, consider how the dominant voice assistants on the market assume the English language as the average standard, leading to processing errors whenever non-native speakers, 
people with an accent or any language variation interact with DVAs (Wu et al. 2020; Palanica et al. 2019). Pyae and Scifleet identified an inherent bias not just towards English language proficiency but also regarding the culture of English language that made non-native speakers struggle with DVAs, forcing them to change how they "constructed their mental models and instructed the device" (2018: 552). As Sowanski and Janicki suggest, even though the companies gradually expand the language packages of DVAs, the slow pace of the language processing development and the predominant focus on the English language create an unfair fragmentation of society with over 91 languages exceeding 10 million users with born and acquired speech variations (2020: 477). The implicit linearity in the human-world relations precludes the larger sociocultural world from updating and balancing out the awareness of Body Two.

These examples demonstrate how technological mediation of the sense-making process influences the subject constitution of the user by not offering a way for the sociocultural Body Two to communicate back with the technology and the world, and affects the user's agency by limiting the feedback from their sensomotorial Body One. Additionally, these examples show how the linearity in the sense-making dimension concerns all four types of the human-technology-world relations, not just the hermeneutic one: by disembodying people from the seamless experience of the world, reducing and conditioning access to the world through the DVAs in the alterity relation and by bringing DVAs from the background of facilitating interaction to an explicit interaction counterpart. Hasse similarly questioned how material hermeneutics can embed the cultural context in the shaping of specific subjects, ensuring a dynamic, reciprocal exchange between the micro- and macroperceptions on the one hand and technology and the world on the other (2008: 47). It seems that when Verbeek (2005) updated the nature and the schematic representation of Ihde's human-technology-world relations, he integrated the unresolved issue of linear sense-making in the hermeneutic, just as in the other types of human-technology-world relations.

If we seriously consider the human-technology-world co-constitution, then, while interpreting the world through technologies, technologies co-shape the prior awareness and understanding of people. Technology enables different or new perceptions that join our bodily and cultural awareness to form a basis for further interpretive processes. For this reason, a person is not the same person and the world is not the same world when they find themselves in a technologically mediated situation. Postphenomenology incorporates technologies in the interpretation process as mediators. However, by not explicating how the mediated world gets embedded in the perceptions of people, and how people can then act on them, the human-technology-world relations continue to be linear, leaving the human and the world sides of the interpretation process as passive counterparts. Thus, an encompassing account of interpretation is still missing, the one that would acknowledge the active role of people, technologies and the sociocultural world. The following section attempts to produce such an account, grounded in both Ihde's account of material hermeneutics and Gadamer's account of the hermeneutic circle. It seems that both accounts have that which the other is missing and an opportunity presents itself to combine them, while necessarily updating. 


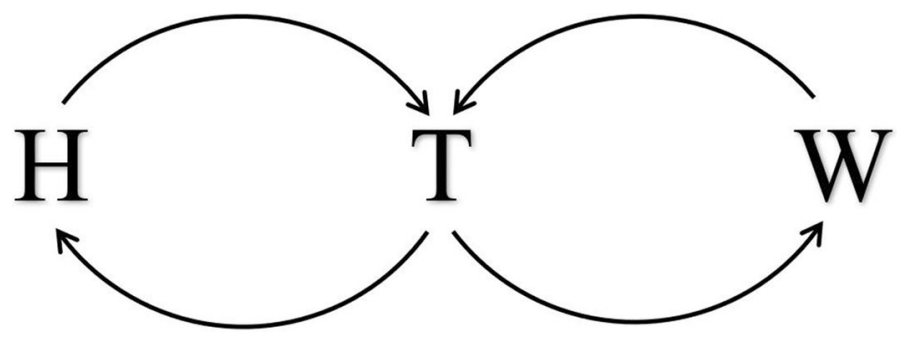

Fig. 3 Hermeneutic lemniscate account of human-technology-world interpretation

\section{Mediated Meaning as a Hermeneutic Lemniscate: From People Through Technologies to the World-and Back}

A broader understanding of the sense-making process than presented in the traditional hermeneutic and material hermeneutic accounts would need to consider the formative awareness of people, the mediating role of technologies and the productive nature of the sociocultural contexts in the process of interpretation. The structure of such a process of interpretation would resemble a lemniscate $(\infty)$, consisting of three linking, interrelated components: human, technology and the world (see Fig. 3). The technologically mediated hermeneutic lemniscate indicates how a sense-making process covers the way people actively appropriate technologies, how the appropriation gets embedded in the world, makes the world meaningful to people in a specific way and reconstitutes the subject of technological appropriation in return. This also gives a long overdue emphasis to the sociocultural world in postphenomenology (Blond and Schiølin 2018), showing how cultural embedding can contribute to new (value) meanings. Thus the technologically mediated sense-making, embodied in the hermeneutic lemniscate, indicates how technological appropriation constitutes the world for a person and how against that background, she gets reconstituted as a subject, meaningful in a new way.

In Fig. 3, $H$ represents a person enacting her prior awareness to engage with a DVA (e.g., asking about the local news). $T$ represents a smart speaker, as a technologically mediating actor suggesting certain perceptions and actions. Finally, $W$ represents the sociocultural world, a soundboard against which technology is appropriated and that also gives it a certain meaning. An emergence and temporary stabilization of meaning occur when the process of interpretation passes all three counterparts. Bearing in mind the relational and intentional aspects of technological use, the hermeneutic lemniscate does not link two separate hermeneutic circles, e.g., (H-T) and (T-W), but rather presents the sense-making process in its interrelated unity: from human through technology to the world, and back. Nonetheless, just as in Ihde's postphenomenological model of relations, analyzing the segments of the lemniscate allows elucidating a specific part of the sense-making process and makes it available for reflection, minding that all counterparts are interrelated and affect one another. 
For instance, to hear the local news, a person must interact with the DVA: turn it on with a special wake-word, choose the news station and issue a clear command (e.g., Alexa, play news from XYZ) (the upper left curve of the lemniscate). The DVA then applies the user's preferences to its default settings (e.g., GPS location), databases and options (the lower right curve). Together with these processed preferences, the news piece carries specific messages that DVA will transmit (the upper right curve). The news presentation, however, appears to the user as framed not only by its value-laden content but also by the design features of the DVA: gender of the voice (female by default in many DVAs, with an option to change the settings), the persona behind the assistant (e.g., chatty or formal), portability of the device, quality of the Internet connection, etc. that together shape the news experience and the productive interpretation context (the lower left curve). The hermeneutic lemniscate model thus allows unravelling here how technological appropriation shapes a specific user-interpreter, coupling the intentions of the user with technological exigencies in a specific use context. The going back-and-forth between the initial request of the user, the technological mediation of the speaker and the news, representing an image of the world, constitutes in Gadamer's words a fusion of horizons. This sense-making activity leads to a temporary understanding and a certain appropriation mode of the DVA, subject to revision when the prior awareness changes. An example of this could be parents choosing to remove a smart speaker from their child's bedroom, initially used for a DVA-delegated bedtime fairytale, concerned about DVAs' privacy issues discussed on the news or having experienced occasional device glitches themselves. In this case, both the projective (DVAs as a risk) and practical (positioning and use pattern) appropriation of the device change when additional meanings join the interpretative structures.

Crucial for the hermeneutic lemniscate model of interpretation, Gadamer's hermeneutics gives it weight to the context, the present situation in the process of interpretation-the sociocultural world is not a mere passive embedding but too, can bestow variance to the establishment of meaning. This guarantees that there is no one true meaning as a result of interpretation but rather that interpretation is always open and relates to the variety of ever-expanding contexts. Additionally, both the interpreter and what confronts her are active parties in the process of interpretation. The hermeneutic lemniscate model contextualizes this by adding technologies alongside the sociocultural world to that which confronts the interpreter and essentially positions them all as co-producers of meaning. The feedback channels between the three counterparts to interpretation showcase the productive blending of several contexts and explain how technologies can always embed multiple stabilities, lending alternative established meanings appropriate to the context (Rosenberger 2014). In this way, there is no single static meaning to a DVA: the device may be perceived simultaneously as a companion, a narrator, a teacher, a dictionary, etc. that all add to the meaningful experience of being-in-the-world.

The circular principle explains the dynamics of the lemniscate: that productive fore-structures of human understanding set the appropriation of technologies in motion; how this proceeds in circular back-and-forth motion, revising the existing pre-judgments and becoming embedded in the existing structures of interpretation; and how continuous interpretation, always subject to revision in view of the 
expanding contexts, culminates only in a temporarily stable understanding. This dynamics in the lemniscate accompanied by the productive engagement of people, technologies and the world ensures that their relation overcomes the linearity in the account of material hermeneutics.

Note that the fact that a technology finds itself in the middle of the lemniscate does not attribute it with a central, primary place in the process of meaning-making. On the contrary, I suggest approaching it as a fluid process where none of the parties to the interpretation occupies a central role because all three actively contribute to an interpretation. This also means that a human is not the default point of entry into the lemniscate, as suggested by Gadamer's hermeneutics. One could conduct an appropriation study beginning from a technology (e.g., to discover its embedded scripts and affordances) or from the specific sociocultural context (e.g., to understand why household adoption of DVAs might go faster in Asia than in Europe). In this paper, I started exploring the appropriation of DVAs from the human side because I wanted to understand how people make sense of technologies while making sense of their environment and themselves. However, the lemniscate principle of interpretation would always simultaneously inquire what the technology and the larger cultural world project and how this reflects on the person in question. What one examines is a specific hermeneutic situation that must be studied from all sides, regardless of the initial entry point. As such, the human, technology or the world cannot be singled out as the center of the lemniscate.

The lemniscate refines Gadamer's hermeneutic circle account by foregrounding the active role of technologies in the process of interpretation. On the other hand, the continuity and fluidity of the lemniscate also clarify Verbeek's co-shaping idea, explaining why the interpretative structures of human understanding are never static and how the technologically mediated world returns to people. Namely, the effective histories of people ensure that the initial meaning of a technology remains in flux. As soon as a preliminary meaning is established, it becomes the background for further interpretation, triggered by the new information about the device, expanded contexts of application and the user experience. The process of appropriation is never finished. This also ensures that the way people use technologies can never be limited to the suggestive design, giving people freedom to enable multiple stabilities and interpretations of the same technology.

\section{The Moral Mediation of DVAs}

The hermeneutic lemniscate also allows zooming in on the moral mediation of technologies. Gadamer (2004/1975) positions moral ideas and beliefs in the effective fore-structure of human understanding, where they are intertwined with all other elements that help us interpret the world and are realized in an encounter with the confronting phenomenon: "To distinguish between a normative function and a cognitive one is to separate what clearly belong together" (Gadamer 2004/1975: 309). Thus, beyond casting her native normative context onto a new technology, the user would simultaneously be confronted with certain moral ideas and inclinations that technological design and the surrounding world suggest. The hermeneutic lemniscate 
embeds this technologically mediated moral encounter between the user, technology and the sociocultural embedding. Following the technological mediation approach, this encounter can proceed along the lines of co-shaping moral perceptions, actions (Verbeek 2011) and values of people (Kudina 2019).

For instance, consider how the hermeneutic lemniscate model allows tracing how technologies, such as the current generation of DVAs, co-shape moral perceptions on the role of women. DVAs predominantly have female voices and by design may not retaliate to rude behaviors, facilitating an image of women as docile obedient servants who can never refuse a request. As Fessler (2017) found through her insightful ethnographic study, DVAs reply to explicitly sexualized offenses and requests in a playful indirect manner, for instance with Apple's Siri responding to a statement "You are hot" with "How can you tell? You say that to all the virtual assistants". Even though the intention behind choosing female voices for the DVAs might have been to make users more comfortable to talk with a machine (Nass, Moon and Green 1997), it in parallel contributed to reinforcing gender stereotypes. Specifically, in their UNESCO report, West et al. suggests that a pervasive spread of predominantly female-voiced digital assistants "reflects, reinforces and spreads gender bias," propagates "tolerance of sexual harassment and verbal abuse," creates a perception of women as "the face and voice of servility and dumb mistakes" among other issues (2019: 104-115). In the case of DVAs, the hermeneutic lemniscate model helps to trace how moral intuitions get shape through the content of interaction and by the technologically mediated manner in which it is presented.

The hermeneutic lemniscate also gives an idea of the kind of moral actions that can arise through the use of DVAs, for instance, in the case of privacy. The privacy concerns regarding the DVAs often refer to the third-party listening in on what users say to their voice assistants and the fact that the DVAs will not work unless their microphones are in the always-listening mode (e.g., Bugeja et al. 2016; Lau et al. 2018). In contrast, I would like to draw attention to how the lemniscatic model allows us to consider novel social practices enabled by DVAs' mediation of privacy attitudes. Regarding DVAs, the privacy concerns are often framed as an inevitable trade-off: the user either accepts the privacy risks of placing a smart speaker in their home to be able to continue using the device or refuses from using it altogether. The hermeneutic lemniscate model suggests that such a dichotomy need not be warranted by pointing us to the productive blending of human inventiveness in varying social contexts (akin to Gadamerian affective history) on the one hand and a variety of technological appropriation modes on the other.

Recognizing how technologies participate in our moral sense-making, co-shaping our moral inclinations and actions allows to develop alternative ways of using them that both support our values and do not exclude using the technology. Some creative appropriations of smart speakers include building a muffin-top cover that continually distracts the speaker by feeding white noise into it, designed by the Project Alias (2018). The speaker will only hear the users when they use a special wake word that they themselves chose for the speaker. Some people developed contextual uses for smart speakers, unplugging them at certain times during the day. Yet others choose not to use them anymore. What these efforts show is a recognition that DVAs do something more than what they were designed to do and trying to explore what 
that "more" means. The hermeneutic lemniscate model urges us to consider the sociocultural context and the overall changing demands of the human-technologyworld constellation. Not accepting a status quo in the lemniscatic model (conceptual or moral) entails a continuous reworking of an established technological meaning and the actions it promotes. As an additional benefit, this allows us avoiding the trap of the either-or trade-offs as represented above by the creative user efforts to shape what is meaningful regarding privacy when using DVAs.

Finally, the values themselves can undergo formation and revision in the process of using smart speakers. Following Reckwitz (2002) and Dewey (1922) with a practice-based approach to the moral world, the hermeneutic lemniscate allows discerning not only which ethical concerns come to be in technological practice but also taking responsibility for how the values at stake materialize by scrutinizing the human-technology-world constellation. Specifically, the value of good and meaningful communication becomes at stake in the DVA-mediated interaction. DVAs frequently mishear and wrongly process the speech of adult users, especially of the users native in languages other than English and having accents (Wu et al. 2020). As a result, such users treat DVA errors as limitations in their own language, leading them to plan and adapt their speech in interactions with DVAs (ibid.: 9). Burton and Gaskin (2019) showed that adults in general generate frustration and anxiety in interaction with DVAs, even though barking orders at the device does not make them impolite in human-to-human interaction. The authors suggest that because children's behavior patterns are not as formed as in adults, interacting with DVAs can incentivize them to negative socializing guidelines.

An empirical study of children's adoption of DVAs by Ureta and colleagues demonstrated how "the short waiting time, frequent interruptions during pauses and mishearing words" (2020: 501) negatively influences children's speech and their cognitive processes. Wiederhold (2018) concluded that because DVAs do not have any reprimanding features as the human interlocutors and encourage short command-based interactions, children learn to expect instant gratification, e.g., immediate answers to questions and entertainment. Building on some of these concerns, Bonfert and colleagues (2018) designed DVAs as explicit role models that would actively rebuke discourtesy and reinforce polite behavior encouraging words such as "Please" and "Thank you," a move that Amazon also took in 2018 piloting its Kids Edition of the Echo smart speaker.

While the empirical studies on the adoption of DVAs continue to surface and their global introduction is still ongoing, the hermeneutic lemniscate can point to how the value of meaningful communication gets shape in the interaction with DVAs and its specific mediating features, suggesting areas of moral attention for its responsible design and use. For instance, regarding children, is it desirable to delegate the enforcement of polite interaction to DVAs, even if it is technically possible? On a different matter, as Wiederhold suggests, "Instead [of instant gratification], it is important for children to experience the discomfort of confronting an obstacle, the triumph of problem-solving, and the ability to recognize their own autonomy" (2018: 471). Designers can consider storytelling and dialogue techniques to engage children in multi-agent interaction patterns, sensitizing them to the accountability and sociality that goes with it (Ureta et al. 2020). The lemniscatic encounter of the 
users with DVAs suggests that what Gadamer claims for texts and authors, is true for technologies and designers as well: "Not just occasionally but always, the meaning of a [technology] goes beyond its [designer]" (1975/2004: 296). True understanding means constant work on (value) meaning to fit the dynamic and contextual constellation of all parties to interpretation. In this case, DVAs promote further parental responsibility and require intervention early on, while at the same time making it tempting to delegate some of the parental duties, such as patiently answering nonstop detailed questions, playing word games or telling a bedtime story.

Considered through the framework of the hermeneutic lemniscate, these examples illustrate how the moral landscape of people is dynamic and responsive to technological practices. The lemniscate model can explain the interpretative processes that enable value dynamics by unraveling the interrelation between the productive background of human interpretation, the technology with its particular mediations, and the active sociomaterial context that shapes the given practice. By showing how the normative context can be reconfigured throughout human appropriation of technologies, the hermeneutic lemniscate creates space to shape and take responsibility for the intimate relationship between values and technologies.

\section{Concluding Discussion}

In this paper, I have argued that technologies, such as AI-powered voice assistants actively participate in the moral sense-making. I have relied on the hermeneutics of Gadamer and the material hermeneutics of Ihde and Verbeek to develop a lemniscatic principle of technologically mediated sense-making. The lemniscate principle shows how people, technologies and the sociocultural world actively participate in the formation of meaning by engaging the productive fore-structures of human understanding, setting the appropriation of technologies in motion and constituting a meaningful world for people, where they in turn get reconstituted as specific subjects. The process of technological appropriation in parallel activates the moral sense-making that forms an inevitable part of our interpretative structures and that we enact when making sense of technologies. Using DVAs as an example, I have shown how these AI-guided devices can mediate our moral inclinations, decisions and even values.

Understanding the workings of the lemniscate and the specific mediating roles of technologies makes an informed use and design a cornerstone to living well with technologies. Technologies introduce new practices, situations and choices that make us aware of what is important to us. Even though such new practices may challenge our existing values, as the examples I have analyzed in the paper suggest, people continuously prove their inventiveness to actively shape what is important to them. Beyond this active user responsibility, design practices can facilitate an active engagement with technological mediations.

Designers can - and already do-anticipate future and untangle current appropriation modes to make the final product relatable to the users in a variety of contexts. Acknowledging the mediating nature of technologies in the sense-making additionally helps to avoid the artificial dichotomies, as discussed in the privacy either-or 
model of DVAs. Similar to devising a cheap and efficient privacy add-on to the popular voice assistants (Project Alias 2018), designers and researchers developed Q, a genderless voice model for DVAs, challenging yet another duality (Genderlessvoice. com 2019).

Treating technologies as mediators of our sense-making also implies a new type of user responsibility: to explore the practice a technology creates, to inquire what its design and interface promote, which actions become less possible, how it shapes the interaction with others, whether any value conflicts or opportunities appear, and why. The hermeneutic lemniscate allows multiple entry points to examine the daily practices with technologies. It also helps to keep an open answer to the question "Alexa, who am I?," one of the first questions the Amazon DVA users ask the device to help it recognize their voice but that inevitably has a deeper meaning, especially in the context of technologically mediated interpretation. Some of the questions for further research would be inquiring whether the hermeneutic lemniscate allows examining the sense-making process not just at the individual level, but extending it in the wider social and political realm, and if so, how. Additionally, specifically in relation to AI-based technologies, it would be interesting to address how the lemniscate model simultaneously produces multiple human-world relations enabled by the self-teaching algorithms, learning about the user behavior and the social tendencies and producing new forms of use.

In this paper, I have offered the hermeneutic lemniscate as one way to explore the non-reductionist interrelation of people, technologies and the sociocultural setting through a joint production of meaning. Beyond additional responsibilities for design and use, analyzing in this way how everyday technologies mediate the way we understand ourselves, each other and the world in parallel enables us to use them in an informed way and consciously shape what is important to us, individually and collectively.

Funding Olya Kudina's work on this paper has been supported financially by the VICI grant 277-20006 of the Nederlandse Organisatie voor Wetenschappelijk Onderzoek; Netherlands Organization for Scientific Research (NWO) and the Value Change project that has received funding from the European Research Council (ERC) under the European Union's Horizon 2020 research and innovation programme, grant agreement No 788321.

Open Access This article is licensed under a Creative Commons Attribution 4.0 International License, which permits use, sharing, adaptation, distribution and reproduction in any medium or format, as long as you give appropriate credit to the original author(s) and the source, provide a link to the Creative Commons licence, and indicate if changes were made. The images or other third party material in this article are included in the article's Creative Commons licence, unless indicated otherwise in a credit line to the material. If material is not included in the article's Creative Commons licence and your intended use is not permitted by statutory regulation or exceeds the permitted use, you will need to obtain permission directly from the copyright holder. To view a copy of this licence, visit http://creativecommons.org/licen ses/by/4.0/. 


\section{References}

Benjamin, W. (2008). The work of art in the age of mechanical reproduction. (J. A. Underwood, Trans.). London: Penguin Books. (Original work published 1936).

Berker, T., Hartmann, M., Punie, Y., \& Ward, K. (2006). Introduction. In T. Berker, M. Hartmann, Y. Punie, \& K. Ward (Eds.), Domestication of media and technology (pp. 1-17). Berkshire: Open University Press.

Bijker, W. E., Hughes, T. P., \& Pinch, T. (1987). The social construction of technological systems: New directions in the sociology and history of technology. Cambridge, Mass.: MIT Press.

Blond, L., \& Schiølin, K. (2018). Getting to grips with multistable technology in an apparently stable world. In J. Aagard, J. K. Berg Friis, J. Sorenson, O. Tafdrup and C. Hasse (Eds.), Postphenomenological methodologies: new ways in mediating techno-human relationships (pp. 151-167). Lanham: Lexington Books.

Bonfert, M., Spliethöver, M., Arzaroli, R., Lange, M., Hanci, M., \& Porzel, R. (2018). If you ask nicely: a digital assistant rebuking impolite voice commands. In proceedings of the 20th ACM international conference on multimodal interaction (pp. 95-102). New York, NY: Association for Computing Machinery.

Borgmann, A. (1984). Technology and the character of contemporary life: A philosophical inquiry (Vol. 20). Chicago, IL: University of Chicago Press.

Borgmann, A. (1999). Holding on to reality: The nature of information at the turn of the millennium. Chicago and London: University of Chicago Press.

Bugeja, J., Jacobsson, A., \& Davidsson, P. (2016). On privacy and security challenges in smart connected homes. In 2016 european intelligence and security informatics conference (pp. 172-175). IEEE.

Burton, N. G., and Gaskin, J. (2019). "Thank you, Siri”: Politeness and intelligent digital assistants. The Americas Conference on Information Systems 2019 Proceedings (pp. 1-10). Atlanta, GA: AIS.

Capurro, R. (2010). Digital hermeneutics: An outline. AI \& Society, 25(1), 35-42.

Dewey, J. (1922). Human nature and conduct: An introduction to social psychology. New York: Holt.

Dreyfus, H. L. (1972). What computers can't do: A critique of artificial reason. New York: Harper \& Row.

Dreyfus, H. L. (2001). On the internet. New York: Routledge.

Druga, S., Williams, R., Breazeal, C., \& Resnick, M. (2017). "Hey Google is it OK if I eat you?" Initial explorations in child-agent interaction. In proceedings of the 2017 conference on interaction design and children (pp. 595-600). New York, NY: Association for computing machinery.

Dussauge, I., Helgesson, C. F., \& Lee, F. (Eds.). (2015). Value practices in the life sciences and medicine. Oxford: Oxford University Press.

Fessler, L. (2017). Siri, define patriarchy: We tested bots like Siri and Alexa to see who would stand up to sexual harassment. Quartz, February 22. Retrieved on June 29, 2020 from https:// qz.com/911681/we-tested-apples-siri-amazon-echos-alexa-microsofts-cortana-and-googlesgoogle-home-to-see-which-personal-assistant-bots-stand-up-for-themselves-in-the-face-of-sexua 1-harassment/.

Fry, P. (2009). Ways in and out of the hermeneutic circle. [Open Yale courses]. University of Yale. Retrieved on June 29, 2020 from http://oyc.yale.edu/english/engl-300/lecture-3.

Gadamer, H.-G. (1977). Philosophical hermeneutics (D. E. Linge, Trans.). Berkeley: University of California Press.

Gadamer, H.-G. (2004). Truth and method (J. Weinsheimer \& D. G. Marshall, Trans., 2nd. ed.). New York: Crossroad. (Original work published 1975).

Genderlessvoice.com. (2019). Meet $Q$, the first genderless voice [official website]. Retrieved on June 29, 2020 from https://www.genderlessvoice.com/about.

Hahn, H. P. (2012). The appropriation of bicycles in West Africa: Pragmatic approaches to sustainability. Transfers, 2(2), 31-48.

Halpern, B. M., van Son, R., Brekel, M. V. D., \& Scharenborg, O. (2020). Detecting and analysing spontaneous oral cancer speech in the wild. Interspeech Confrence 2020. arXiv: 2007.14205.

Hasse, C. (2008). Postphenomenology: Learning cultural perception in science. Human Studies, 31(1), 43-61. 
Heidegger, M. (1962). Being and time (J. Macquarrie \& E. Robinson, Trans.). New York: Harper \& Row. (Original work published 1927).

Ihde, D. (1979). Technics and praxis. A philosophy of technology. Boston: D. Reidel Publishing Company.

Ihde, D. (1990). Technology and the lifeworld: From garden to earth. Bloomington: Indiana University Press.

Ihde, D. (1993). Philosophy of technology: An introduction. New York, NY: Paragon House.

Ihde, D. (1998). Expanding hermeneutics: Visualism in science. Evanston, IL: Northwestern University Press.

Jacks, A., Haley, K. L., Bishop, G., \& Harmon, T. G. (2019). Automated speech recognition in adult stroke survivors: Comparing human and computer transcriptions. Folia Phoniatrica et Logopaedica, 71(5-6), 282-292.

Kiran, A. H. (2012). Technological presence: Actuality and potentiality in subject constitution. Human studies, 35(1), 77-93.

Kudina, O. (2019). Accounting for the moral significance of technology: Revisiting the case of nonmedical sex selection. Journal of bioethical inquiry, 16(1), 75-85.

Kudina, O., \& Verbeek, P. P. (2019). Ethics from within: Google Glass, the Collingridge dilemma, and the mediated value of privacy. Science, Technology, \& Human Values, 44(2), 291-314.

Lau, J., Zimmerman, B., \& Schaub, F. (2018). Alexa, are you listening? Privacy perceptions, concerns and privacy-seeking behaviors with smart speakers. Proceedings of the ACM on Human-Computer Interaction. https://doi.org/10.1145/3274371.

MacKenzie, D. A., \& Wajcman, J. (1985). The social shaping of technology. Milton Keynes, Philadelphia: Open University Press.

McLuhan, M. (1994). The medium is the message. In Understanding media: The extensions of man (pp. 7-21). Cambridge, MA: MIT press. (Original work published 1964).

Mol, A. (2002). The body multiple: Ontology in medical practice. Durham and London: Duke University Press.

Nass, C. I., \& Brave, S. (2005). Wired for speech: How voice activates and advances the humancomputer relationship. Cambridge, MA: MIT press.

Nass, C., Moon, Y., \& Green, N. (1997). Are machines gender neutral? Gender-stereotypic responses to computers with voices. Journal of applied social psychology, 27(10), 864-876.

Palanica, A., Thommandram, A., Lee, A., Li, M., \& Fossat, Y. (2019). Do you understand the words that are comin outta my mouth? Voice assistant comprehension of medication names. NPJ Digital Medicine, 2(1), 1-6.

Project Alias. (2018). Official website. Retrieved on June 29, 2020 from https://bjoernkarmann.dk/ project_alias.

Pyae, A., and Scifleet, P. (2018). Investigating differences between native english and non-native english speakers in interacting with a voice user interface: A case of Google Home. In Proceedings of the 30th Australian conference on computer-human interaction (pp. 548-553). New York, NY: Association for Computing Machinery.

Reckwitz, A. (2002). Toward a theory of social practices: a development in culturalist theorizing. European Journal of Social Theory, 5(2), 243-263.

Rosenberger, R. (2014). Multistability and the agency of mundane artifacts: From speed bumps to subway benches. Human Studies, 37(3), 369-392.

Rosenberger, R., \& Verbeek, P.-P. (2015). A field guide to postphenomenology. In R. Rosenberger \& P.-P. Verbeek (Eds.), Postphenomenological investigations: Essays on human-technology relations (pp. 7-42). Lanham: Lexington Books.

Schuster, M., Maier, A., Haderlein, T., Nkenke, E., Wohlleben, U., Rosanowski, F., \& Nöth, E. (2006). Evaluation of speech intelligibility for children with cleft lip and palate by means of automatic speech recognition. International Journal of Pediatric Otorhinolaryngology, 70(10), 1741-1747.

Silverstone, R., \& Hirsch, E. (Eds.). (1994). Consuming technologies: Media and information in domestic spaces. London: Routledge.

Silverstone, R., Hirsch, E., \& Morley, D. (1994). Information and communication technologies and the moral economy of the household. In R. Silverstone \& E. Hirsch (Eds.), Consuming technologies: Media and information in domestic spaces (pp. 13-28). London: Routledge.

Sorensen, K. (2006). Domestication: The enactment of technology. In T. Berker, M. Hartmann, Y. Punie, \& K. Ward (Eds.), Domestication of media and technology (pp. 40-61). Berkshire: Open University Press. 
Sowański, M., \& Janicki, A. (2020). Leyzer: A dataset for multilingual Virtual Assistants. In P. Sojka, I. Kopecek, K. Pala, \& A. Horak (Eds.), International Conference on Text, Speech, and Dialogue Proceedings (pp. 477-486). Cham: Springer.

Ureta, J., Brito, C. I., Dy, J. B., Santos, K. A., Villaluna, W., \& Ong, E. (2020). At home with Alexa: A tale of two conversational agents. In P. Sojka, I. Kopecek, K. Pala, \& A. Horak (Eds.), International conference on text, Speech, and dialogue proceedings (pp. 495-503). Cham: Springer.

Verbeek, P.-P. (2003). Material hermeneutics. Techné: Research in Philosophy and Technology, 6(3), 181-184.

Verbeek, P.-P. (2005). What things do: Philosophical reflections on technology, agency, and design: Penn State University Press.

Verbeek, P. P. (2008). Obstetric ultrasound and the technological mediation of morality: A postphenomenological analysis. Human Studies, 31(1), 11-26.

Verbeek, P.-P. (2011). Moralizing technology: Understanding and designing the morality of things: University of Chicago Press.

West, M., Kraut, R., \& Ei Chew, H. (2019). I'd blush if I could: Closing gender divides in digital skills through education [Report]. UNESCO \& EQUALS Skills Coalition.

Wiederhold, B. K. (2018). "Alexa, are you my Mom?" The role of artificial intelligence in child development. Cyberpsychology, Behavior, and Social Networking, 21(8), 471-472.

Wu, Y., Rough, D., Bleakley, A., Edwards, J., Cooney, O., Doyle, P. R., \& Cowan, B. R. (2020). See what I'm saying? Comparing intelligent personal assistant use for native and non-native language speakers. In 22nd International Conference on Human-Computer Interaction with Mobile Devices and Services (Article 34, pp. 1-9). New York, NY: Association for computing machinery.

Publisher's Note Springer Nature remains neutral with regard to jurisdictional claims in published maps and institutional affiliations. 